九州大学学術情報リポジトリ

Kyushu University Institutional Repository

\title{
Direct substitution of the hydroxy group with highly functionalized nitrogen nucleophiles catalyzed by $\mathrm{Au}$ (III)
}

Ohshima, Takashi

Graduate School of Pharmaceutical Sciences, Kyushu University and CREST, JST, Fukuoka

Nakahara, Yasuhito

Department of Chemistry, Graduate School of Engineering Science, Osaka University and CREST, JST, Osaka

Ipposhi, Junj i

Department of Chemistry, Graduate School of Engineering Science, Osaka University and CREST, JST, Osaka

Miyamoto, Yoshiki

Department of Chemistry, Graduate School of Engineering Science, Osaka University and CREST, JST, Osaka

他

http://hdl. handle. net/2324/25681

出版情報: Chemical Communications. 47 (29)，pp.8322-8324，2011-08-07. RSC Publishing バージョン:

権利関係: (C) The Royal Society of Chemistry 2011 


\title{
Direct substitution of the hydroxy group with highly functionalized nitrogen nucleophiles catalyzed by $\mathrm{Au}(\mathrm{III}) \dagger$
}

\author{
Takashi Ohshima, ${ }^{a}$ Yasuhito Nakahara, ${ }^{b}$ Junji Ipposhi, $^{b}$ Yoshiki Miyamoto $^{b}$ and Kazushi Mashima $*^{b}$
}

\begin{abstract}
A direct catalytic substitution of various allylic and benzylic alcohols with synthetically useful, but acid-sensitive Boc, Bus, and Dios protected amine nucleophiles, which have not been well utilized for Lewis acid catalysis, with various functionalities (OTBS, OTHP, etc.) were efficiently catalyzed by $1 \mathrm{~mol} \%$ of $\mathrm{Au}(\mathrm{III})$ under mild conditions.
\end{abstract}

The development of a direct and reliable synthetic methodology to attain a wide variety of amine derivatives has attracted considerable attention because of their relevance as synthetic tools for various pharmaceuticals and fine chemicals. Nucleophilic substitution of allylic substrates represents one of the most powerful methods for producing allylamines. ${ }^{1}$ From both environmental and economic points of view, the direct catalytic amination of underivatized allylic alcohols $\mathbf{1}$, which forms water as the sole coproduct, is desirable (Scheme 1). Because of the poor leaving ability of the hydroxyl group, such direct reactions have been rarely explored except for several palladium-catalyzed direct aminations of $\mathbf{1}$ via a $\pi$-allylpalladium intermediate (path $a$ ). ${ }^{2}$ We recently reported that platinum complexes bearing DPEphos or Xantphos ligand are efficient catalysts for direct amination of $\mathbf{1}$ with high monoallylation selectivity and broad substrate generality. ${ }^{3}$ Although these reactions efficiently proceed with electron-rich amines, electrondeficient nitrogen nucleophiles are not good substrates due to their low nucleophilicity. ${ }^{2 e}$ The reaction with electron-deficient nitrogen nucleophiles was efficiently catalysed by various Lewis acids (Re, ${ }^{4} \mathrm{Ru},{ }^{5}$ rare earth metals $,{ }^{6} \mathrm{Au},{ }^{7} \mathrm{In},{ }^{8} \mathrm{Bi},{ }^{9} \mathrm{Fe},{ }^{10} \mathrm{Ag},{ }^{11} \mathrm{Mo},{ }^{12}$ $\mathrm{Hg}^{13}$ etc.) and Brønsted acid ${ }^{14}$ via a carbocation intermediate (path $b){ }^{15}$ Thus, acid-catalyzed direct amination is a counterpart of late transition metal-catalyzed amination; ${ }^{16}$ nucleophiles of the reported acid-catalyzed reaction, however, are limited to rather stable nitrogen compounds such as 4-nitroaniline, tosylamide, methyl carbamate, and simple amides. In particular, there is almost no access to more useful but acid-sensitive nucleophiles such as tert-butyl carbamate. ${ }^{8 b, 10 e, 12 a}$ Here, we report that direct substitutions of allylic and benzylic alcohols with synthetically useful tert-butoxycarbonyl (Boc), thiophenesulfonyl, ${ }^{17}$ tertbutylsulfonyl (Bus), ${ }^{18}$ and 2-(1,3-dioxan-2-yl)ethylsulfonyl $\left(\right.$ Dios) ${ }^{19}$ protected amine nucleophiles are efficiently catalyzed by $1 \mathrm{~mol} \%$ of $\mathrm{NaAuCl}_{4} \cdot 2 \mathrm{H}_{2} \mathrm{O}$ under mild conditions (rt to $40{ }^{\circ} \mathrm{C}$ ). Reactions with more acid-sensitive functional groups such as TBS and THP groups were achieved using dichloro(pyridine-2carbozylato)gold (III) $(\mathbf{4})^{20}$ as a catalyst. Moreover, we found

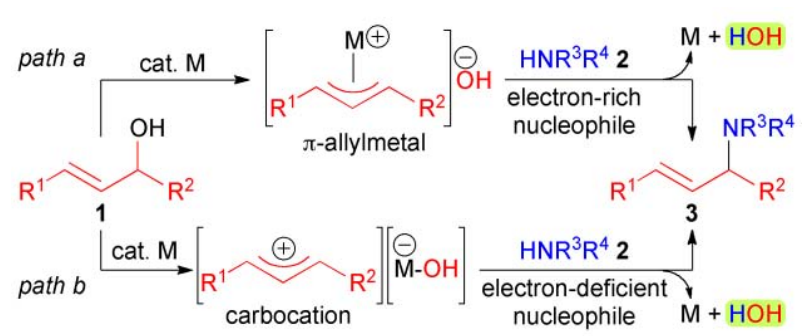

Scheme 1 Direct catalytic amination of allylic alcohol 1.

unusual positive effects of added thiophene in the gold-catalyzed direct amination reactions.

Using the protocol based on Pt-Xantphos, ${ }^{3}$ substrate generality was not expandable to electron-deficient amines. The reaction of 1,3-diphenylprop-2-en-1-ol (1a) with electron-deficient Bocamide 2a (eq 1) using the Pt catalyst gave product 3aa in low yield $(<14 \%) . \dagger$ We are interested in the use of $A u(I)$ and $A u(I I I)$ salts, ${ }^{21}$ which are respectively isoelectronic to $\operatorname{Pt}(0)$ and $\mathrm{Pt}(\mathrm{II})$. Both $\mathrm{AuCl}$ and $\mathrm{AuCl}_{3}$ became catalysts for the reaction of $\mathbf{1 a}$ with 2a and product 3aa was obtained in $92 \%$ and $94 \%$ yield, respectively, after optimization of the reaction conditions. $\dagger$ The use of $\mathrm{NaAuCl}_{4} \cdot 2 \mathrm{H}_{2} \mathrm{O},{ }^{7 \mathrm{a}, \mathrm{be}, \mathrm{f}}$ also gave a high yield $(96 \%)$ and thus we decided to use more stable and easier to handle $\mathrm{NaAuCl}{ }_{4} \cdot 2 \mathrm{H}_{2} \mathrm{O}$ as the catalyst for further studies.

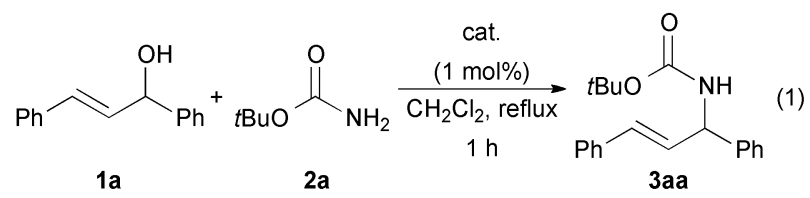

Under the optimized conditions, direct amination of 1a with various $N$-substituted Boc-amides was examined (Table 1, Entries 1-13). Benzyl, allyl, phenethyl, and carbonylmethyl substituted Boc-amides $\mathbf{2 b}-\mathbf{g}$ were good nucleophiles to give the desired products in high yield (Entries 1-6), except for the reaction with a sterically congested $\mathbf{2 h}(\mathrm{R}=c \mathrm{Hex})$ (Entry 7). Under the present reaction conditions, several functionalities such as nitrile (Entry 3), TBS ether of phenol (Entry 5), and ester (Entry 6) remained intact. We further examined the compatibility of other functional groups under the $\mathrm{NaAuCl}_{4}$-catalyzed conditions (Entries 8-13). Nucleophiles with acetoxy (Entry 8) and MEM ether (Entry 9) functionalities reacted smoothly to give the product in excellent yield, whereas TBS (Entry 10) and highly acid-sensitive THP 
Table 1 Direct catalytic substitution of 1 a with various $N$-nucleophile. ${ }^{a}$

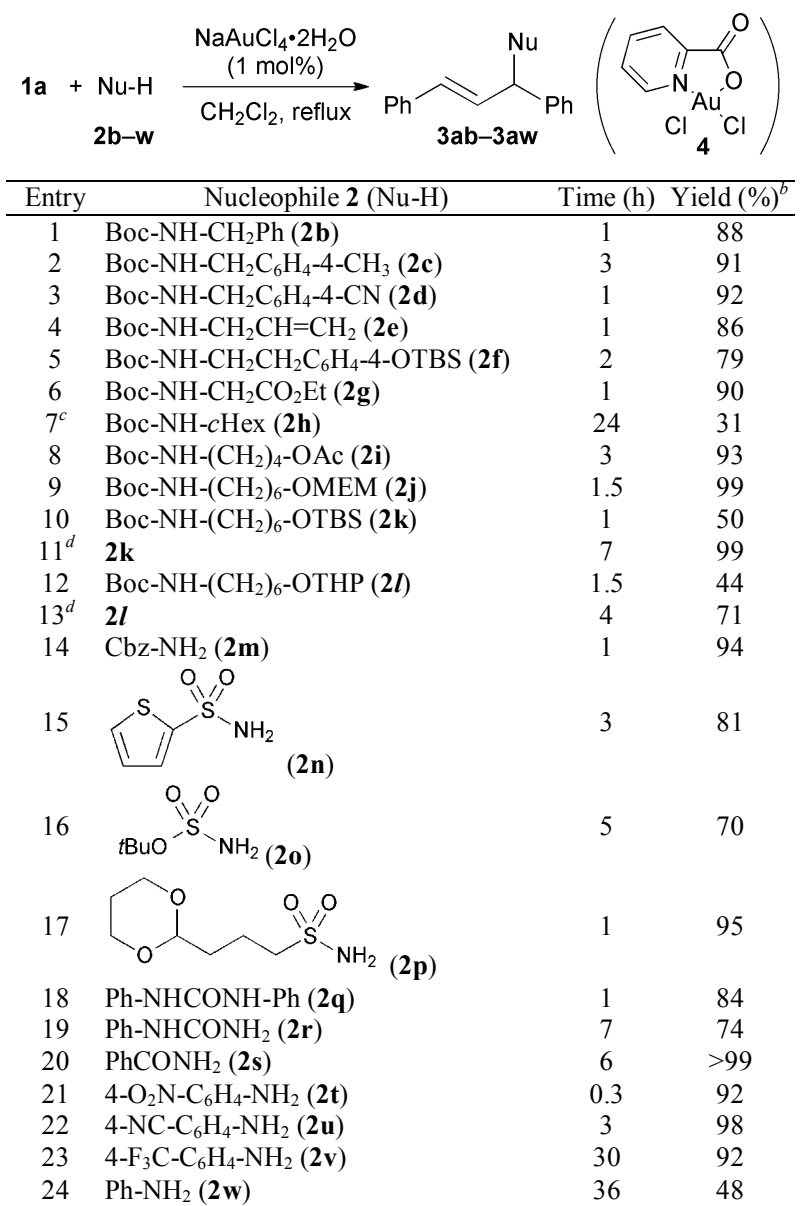

${ }^{a}$ Reaction conditions: $1 \mathrm{a}(1 \mathrm{mmol}), 2$ ( $1.5 \mathrm{mmol}, 1.5$ equiv), $\mathrm{NaAuCl}_{4} \cdot 2 \mathrm{H}_{2} \mathrm{O}(0.01 \mathrm{mmol}, 1 \mathrm{~mol} \%), \mathrm{CH}_{2} \mathrm{Cl}_{2}(2 \mathrm{~mL})$, reflux. ${ }^{b}$ Isolated yield. ${ }^{c}$ Toluene (reflux) was used instead of $\mathrm{CH}_{2} \mathrm{Cl}_{2} \cdot{ }^{d} \mathrm{Au}(\mathrm{III})$-picolinate complex 4 was used instead of $\mathrm{NaAuCl}_{4} \cdot 2 \mathrm{H}_{2} \mathrm{O}$.

(Entry 12) ethers of aliphatic alcohol partially decomposed during the reactions, resulting in only moderate yield of the products. Such undesired decompositions were successfully suppressed by the use of milder $\mathrm{Au}$ (III)-picolinate complex $\mathbf{4}^{20}$ as the catalyst, affording the products 3ak and 3al in 99\% (Entry 11) and 71\% (Entry 13) yields, respectively. We next examined the reaction of 1 a with different types of nitrogen nucleophiles (Entries 14-24). The reaction with $\mathrm{Cbz}$-amide $\mathbf{2} \mathbf{m}$ afforded the corresponding product 3am in 94\% yield (Entry 14). Synthetically useful thiophenesulfonyl (Entry 15), ${ }^{17}$ Bus (Entry 16), ${ }^{18}$ and Dios (Entry 17) ${ }^{19}$ amides, which are readily deprotected by $\mathrm{Mg}$, TFA with anisole, and aq. TFA, respectively, to give the corresponding amines, were first utilized in the direct catalytic amination reaction. They smoothly reacted with $\mathbf{1 a}$ to give the product $\mathbf{3 a n}-$ ap in $70-95 \%$ yield, leaving thienyl, tert-butyl, and acetal functionalities intact. When ureas 2q (Entry 18) and 2r (Entry 19) were used, only mono allylation occurred in both cases. Although amide $2 \mathbf{s}$ was less reactive than the above nucleophiles, the desired product 2 as was obtained in $>99 \%$ yield (Entry 20 ). Electron-deficient aniline derivatives $\mathbf{2 t}-\mathbf{v}$ were also good nucleophiles (Entries 21-23). Electron-rich aniline (2w) is a challenging substrate for the acid-catalyzed direct substitution reaction with a few excellent exceptions. ${ }^{4 a}$ Under the present
Table 2 Direct catalytic substitution of various alcohols with $\mathbf{2 a}{ }^{a}$

Entry

${ }^{a}$ Reaction conditions: $1 \mathrm{a}(1 \mathrm{mmol}), \mathbf{2}(1.5 \mathrm{mmol}, 1.5$ equiv), $\mathrm{NaAuCl}_{4} \cdot 2 \mathrm{H}_{2} \mathrm{O}(0.01 \mathrm{mmol}, 1 \mathrm{~mol} \%), \mathrm{CH}_{2} \mathrm{Cl}_{2}(2 \mathrm{~mL})$, reflux. ${ }^{b}$ Isolated yield. ${ }^{c}$ A mixture of regioisomers (ca. 1:1) was obtained. ${ }^{d} \alpha$-Methyl cinnamylamine derivative was obtained. ${ }^{e}$ The reaction was performed with thiophene (5,1 mmol, 1.0 equiv).

conditions, the desired product 3aw was obtained, though the yield was moderate (Entry 24).

The scope of the reaction with respect to alcohols 1 was further examined (Table 2). The reactions of 1,3-diphenyl substituted allylic alcohols with both electron-donating (Entry 1) and electron-withdrawing (Entry 2) groups proceeded smoothly to afford products $3 \mathbf{b a}$ and $\mathbf{3 c a}$ in $96 \%$ and $94 \%$ yields, respectively. The reactivity of alkyl substituted allylic alcohols 1d (Entry 3) and 1e (Entry 4) was lower than that of $\mathbf{1 a - c}$ due to the formation of less reactive $\alpha$-methyl cinnamyl alcohols, and $\mathrm{S}_{\mathrm{N}} 2^{\prime}$ products (cinnamylamine derivatives) were obtained regioselectively. Benzylic alcohols 1f (Entry 6), 1h (Entry 9), and 1i (Entry 10) smoothly reacted with $\mathbf{2 a}$, though related benzylic alcohol $\mathbf{1 g}$ (Entry 7) was less reactive. This gold catalysis was also applicable to thiophenemethanol derivatives $\mathbf{1 j}$ (Entry 12) and $\mathbf{1 k}$ (Entry 13), affording the corresponding products in high yield. Because the thiophene unit is rarely utilized in gold catalysis ${ }^{7 \mathrm{~b} .21}$ due to the high affinity of gold to soft sulfur atom, the high yields 
using $\mathbf{2 n}$ (Table 1), $\mathbf{1 j}$, and $\mathbf{1 k}$ were interesting. Contrary to our expectation, thiophene (5) had positive effects on the goldcatalysis and the above-mentioned unsatisfactory results using $1 \mathrm{e}$ and $\mathbf{1 g}$ were greatly improved by the addition of 1 equiv of $\mathbf{5}$, giving products 3ea (Entry 5) and 3ga (Entry 8) in 75\% and $>99 \%$ yields, respectively. Notably, the addition of $\mathbf{5}$ prevented the undesired isomerization of $\mathbf{1 e}$ to cinnamyl alcohol derivatives. Positive effects of added $\mathbf{5}$ were also observed in the reaction of trityl alcohol (1i) (Entry 11). Finally, crossover experiments indicated that the reaction is reversible under the reaction conditions. $^{9 \mathrm{~b}} \uparrow$ The reaction using optically active $\mathbf{1 h}$ gave only the racemic product $\mathbf{3 h a}$, suggesting carbocation intermediate. $\dagger$

In summary, we developed a direct catalytic substitution of various allylic and benzylic alcohols with synthetically useful, but acid-sensitive Boc, Bus, and Dios-protected amine nucleophiles, which have not been well utilized for Lewis acid catalysis, promoted by $1 \mathrm{~m} \mathrm{ol} \%$ of $\mathrm{NaAuCl}_{4} \cdot 2 \mathrm{H}_{2} \mathrm{O}$ under mild conditions (rt to $40{ }^{\circ} \mathrm{C}$ ). The use of a milder $\mathrm{Au}$ (III)-picolinate complex as a cat alyst enables reactions with more acid-sensitive functional groups, such as TBS and THP groups. Furthermore, a thiophene unit showed unusual positive effects on the present gold catalysis and improved the yield of less reactive substrates.

This work was supported by Grant-in-Aid for Scientific Research (B) and Scientific Research on Innovative Areas from MEXT and CREST from JST. Y.N. thanks Global COE Program of Osaka University. We thank Prof. Tsunoda (Tokushima Bunri Univ.) for a gift of Dios-amides.

\section{Notes and references}

${ }^{a}$ Graduate School of Pharmaceutical Sciences, Kyushu University and CREST, JST, Fukuoka, Japan. Fax\&Tel: +81 92642 6650; E-mail: ohshima@phar.kyushu-u.ac.jp

${ }^{b}$ Department of Chemistry, Graduate School of Engineering Science, Osaka University and CREST, JST, Osaka, Japan. Fax\&Tel: +8166850 6245; E-mail:mashima@chem.es.osaka-u.ac.jp

$\dagger$ Electronic Supplementary Information (ESI) available: experimental procedures, characterization of the products, and other detailed results. See DOI: $10.1039 / \mathrm{b} 000000 \mathrm{x} /$

(1) (a) J. Tsuji, In Transition Metal Reagents and Catalysis; WileyVCH: Weinheim, 2000. (b) B. M. Trost, C. Lee, In Catalytic Asymmetric Synthesis, 2nd ed.; I. Ojima, Ed.; Wiley-VCH: Weinheim, 2000. (c) B. M. Trost, M. L. Crawley, Chem. Rev., 2003, 103, 2921.

(2) (a) F. Ozawa, H. Okamoto, S. Kawagishi, S. Yamamoto, T. Minami, M. Yoshifuji, J. Am. Chem. Soc., 2002, 124, 10968; (b) Y. Kayaki, T. Koda, T. Ikariya, J. Org. Chem., 2004, 69, 2595; (c) H. Kinoshita, H. Shinokubo, K. Oshima, Org. Lett., 2004, 6, 4085; (d) O. Piechaczyk, M. Doux, L. Ricard, P. le Floch, Organometallics, 2005, 24, 124; (e) I. Usui, S. Schmidt, M. Keller, B. Breit, Org. Lett., 2008, 10, 1207; (f) D. Defieber, M. A. Ariger, P. Moriel, E. M. Carreira, Angew. Chem., Int. Ed., 2007, 46, 3139.

(3) (a) M. Utsunomiya, Y. Miyamoto, J. Ipposhi, T. Ohshima, K. Mashima, Org. Lett., 2007, 9, 3371; (b) T. Ohshima, Y. Miyamoto, J. Ipposhi, Y. Nakahara, M. Utsunomiya, K. Mashima, J. Am. Chem. Soc., 2009, 131, 14317.

(4) (a) Z. Zhu, J. H. Espenson, J. Org. Chem., 1996, 61, 324; (b) R. V. Ohri, A. T. Radosevich, K. J. Hrovat, C. Musich, D. Huang, T. R. Holman, F. D. Toste, Org. Lett., 2005, 7, 2501.

(5) (a) Y. Nishibayashi, I. Wakiji, M. Hidai, J. Am. Chem. Soc., 2000, 122, 11019; (b) Y. Nishibayashi, M. D. Milton, Y. Inada, M. Yoshikawa, I. Wakiji, M. Hidai, S. Uemura, Chem. Eur. J., 2005, 11, 1433.

(6) (a) M. Noji, T. Ohno, K. Fuji, N. Futaba, H. Tajima, K. Ishii, J. Org. Chem., 2003, 68, 9340; (b) W. Huang, Q.-S. Shen, J.-L. Wang, X.-G. Zhou, Chin. J. Chem., 2008, 26, 729.
(7) (a) M. Gregory, V. Boucard, V.; J.-M. Campagne, J. Am. Chem. Soc., 2005, 127, 14180; (b) V. Terrasson, S. Marque, M. Georgy, J.-M. Campagne, D. Prima, Adv. Synth. Catal., 2006, 348, 2063; (c) S. Guo, F. Song, Y. Liu, Synlett, 2007, 964; (d) Y. Lu, X. Fu, H. Chen, X. Du, X. Jia, Y. Liu, Adv. Synth. Catal., 2009, 351, 129; (e) O. Debleds, C. D. Zott, E. Vrancken, J.-M. Campagne, P. Retailleau, Adv. Synth. Catal., 2009, 351, 1991; (f) M. Georgy, V. Boucard, O. Debleds, C. Dal Zotto, J.-M. Campagne, Tetrahedron, 2009, 65, 1758; $(g)$ P. Mukherjee, R. A. Widenhoefer, Org. Lett., 2010, 12, 1184.

(8) (a) M. Yasuda, T. Somyo, A. Baba, Angew. Chem. Int. Ed., 2006, 45 793; (b) P. Vicennati, P. G. Cozzi, Eur. J. Org. Chem., 2007, 2248; (c) Y.-L. Liu, L. Liu, D. Wang, Y.-J. Chen, Tetrahedron, 2009, 65, 3473.

(9) (a) Z.- P. Zhan, W.-Z. Yang, R.-F. Yang, J.-L. Yu, J.-P. Li, H.-J. Liu, Chem. Commun., 2006, 3352; (b) H. Qin, N. Yamagiwa, S. Matsunaga, M. Shibasaki, Angew. Chem. Int. Ed., 2007, 46, 409; (c) J. A. R. Salvador, R. M. A. Pinto, S. M. Silvestre, Curr. Org. Synth., $2009,6,426$.

(10)(a) Z.-P. Zhan, J.-L. Yu, H.- J. Liu, Y.-Y. Cui, R.-F. Yang, W.-Z. Yang, J.-P. Li, J. Org. Chem., 2006, 71, 8298; (b) U. Jana, S. Maiti, S. Biswas, Tetrahedron Lett., 2008, 49, 858; (c) K. Y. Lee, H. S. Lee, J. N. Kim, Bull. Korean Chem. Soc., 2008, 29, 1099; (d) F. Shi, M. K. Tse, S. L. Zhou, M. M. Pohl, J. Radnik, S. Hubner, K. Jahnisch, A. Bruckner, M. Beller, J. Am. Chem. Soc., 2009, 131, 1775; (e) A. Guérinot, A. Serra-Muns, C. Gnamm, C. Bensoussan, S. Reymond, J. Cossy, Org. Lett., 2010, 12, 1808; (f) X. Cui, F. Shi, Y. Zhang, Y. Deng, Tetrahedron Lett., 2010, 51, 2048.

(11)B. Sreedhar, P. S. Reddy, M. A. Reddy, B. Neelima, R. Arundhathi, Tetrahedron Lett., 2007, 48, 8174.

(12)(a) C. R. Reddy, P. P. Madhavi, A. S. Reddy, Tetrahedron Lett., 2007, 48, 7169; (b) H. W. Yang, L. Fang, M. Zhang, C. J. Zhu, Eur. J. Org. Chem., 2009, 666; (c) M. Zhang, H. Yang, Y. Cheng, Y. Zhu, C. Zhu, Tetrahedron Lett., 2010, 51, 1176.

(13)(a) K. Namba, Y. Nakagawa, H. Yamamoto, H. Imagawa, M. Nishizawa, Synlett, 2008, 1719; (b) H. Yamamoto, E. Ho, K. Namba, H. Imagawa, M. Nishizawa, Chem. Eur. J., 2010, 16, 11271.

(14)(a) K. Motokura, N. Nakagiri, K. Mori, T. Mizugaki, K. Ebitani, K. Jitsukawa, K. Kaneda, Org. Lett., 2006, 8, 4617; (b) K. Motokura, N. Nakagiri, T. Mizugaki, K. Ebitani, K. Kaneda, J. Org. Chem., 2007, 72, 6006; (c) G. W. Wang, Y. B. Shen, X. L. Wu, Eur. J. Org. Chem., 2008, 4367; (d) C. R. Reddy, E. Jithender, Tetrahedron Lett., 2009, 50, 5633.

(15)For recent reviews of direct catalytic amination reaction of alcohols through redox process, see: (a) M. Hamid, M.; P. A. Slatford, J. M. J. Williams, Adv. Synth. Catal., 2007, 349, 1555; (b) T. D. Nixon, M. K. Whittlesey, J. M. J. Williams, Dalton Trans., 2009, 753; (c) G. Guillena, D. J. Ramon, M. Yus, Chem. Rev., 2010, 110, 1611; (d) G. E. Dobereiner, R. H. Crabtree, Chem. Rev., 2010, 110, 681.

(16)Electron-rich nitrogen nucleophiles, which are efficient for late transition metal-catalyzed direct amination, often deactivate such acid catalysts.

(17)(a) A. S. Gonzlez, R. G. Arrays, J. C. Carretero, Org. Lett., 2006, 8, 2977; (b) H. Morimoto, G. Lu, N. Aoyama, S. Matsunaga, M. Shibasaki, J. Am. Chem. Soc., 2007, 129, 9588.

(18)(a) P. Sun, S. M. Weinreb, M. Shang, J. Org. Chem., 1997, 62, 8604; (b) A. V. Gontcharov, H. Liu, K. B. Sharpless, Org. Lett., 1999, 1, 783.

(19)I. Sakamoto, N. Izumi, T. Yamada, T. Tsunoda, Org. Lett., 2006, 8, 71.

(20)(a) A. S. K. Hashmi, J. P. Weyrauch, M. Rudolph, E. Kurpejovic, Angew. Chem. Int. Ed., 2004, 43, 6545; (b) S. Wang, L. Zhang, J. Am. Chem. Soc., 2006, 128, 8414; (c) S. Wang, L. Zhang, J. Am. Chem. Soc., 2006, 128, 14274; (d) X. Huang, L. Zhang, J. Am. Chem. Soc., 2007, 129, 6398; (e) C. Ferrer, C. H. M. Amijs, A. M. Echavarren, Chem. Eur. J., 2007, 13, 1358.

(21) For recent reviews of gold catalysis, see: (a) A. S. K. Hashmi, G. J. Hutchings, Angew. Chem. Int. Ed., 2006, 45, 7896; (b) A. M. Echavarren, E. Jiménez-Nfflúnez, Chem. Commun., 2007, 333; (c) A. S. K. Hashmi, Chem. Rev., 2007, 107, 3180; (d) A. S. K. Hashmi, Angew. Chem. Int. Ed., 2010, 49, 5232. 